\title{
INTEGRATION BETWEEN UNMANNED AERIAL VEHICLE AND TERRESTRIAL LASER SCANNER IN PRODUCING 3D MODEL
}

\author{
Allysa Mat Adnan, Norhadija Darwin, Mohd Farid Mohd Ariff, Zulkepli Majid, Khairulnizam M Idris
}

Department of Geoinformatics, Faculty of Built Environment and Surveying, Universiti Teknologi Malaysia, 81310 Skudai, Johor lysaroar@gmail.com, norhadija2@utm.my, mfaridma@utm.my, zulkeplimajid@utm.my, khairulnizami@utm.my

KEY WORDS: Integration, UAV, TLS, point clouds, 3D model

\begin{abstract}
:
Unmanned Aerial Vehicles (UAV) frequently used for obtaining 2D or 3D data acquisition. Meanwhile, Terrestrial Laser Scanners (TLS) are used for obtaining only 3D data acquisition. However if both are integrated, they were able to produce a more accurate data. The purpose of this study is to investigate the possible integration of point clouds obtained by TLS with UAV images at T06 FBES building through the aerial survey where the roof is scanned and ground survey which scans the facades' building. Topcon GLS 2000 and DJI Inspire 1 UAV were used to acquire the data at the field. The aerial data and ground data were processed using Pix4D and Scanmaster respectively. The data integration process is done by converting both point clouds into the same coordinate system and then by aligning the same points of both points clouds in Cloud Compare. For verification purposes, dimensional survey was done and there are several distances were taken from the study area to validate the accuracy assessment. The result of residuals between the dimension survey and integration is $0.183 \mathrm{~m}$ which is below 1 meter. The result of this study is a 3D model of UTM T06 FBES building based on the point cloud accuracy in $\mathrm{cm}$ level. To conclude, the integration between these two methods can be implemented to produce an accurate 3D model.
\end{abstract}

\section{INTRODUCTION}

Rapid development in the city has established development and skyscrapers with unique architecture. With the high population density and limited land space, better technology is needed in the management and construction of the future. Thus the possibility of data integration technology has been applied in the measurement to generate $3 \mathrm{D}$ model.

Three-dimensional (3D) mapping and modeling has increased in demand notably in surveying and engineering works. Apart from that, 3D scanning is the act of mapping an object, structure or area and describing it in the form of $\mathrm{x}, \mathrm{y}$ and $\mathrm{z}$ coordinates a format known as a "point cloud". A point cloud is a collection of data points defined by a given coordinates system (Rouse, 2016). Point clouds are used to create 3D meshes and it defines the shape of a physical object or any study area. The most used platforms for 3D mapping works nowadays is Terrestrial Laser Scanner (TLS). Terrestrial Laser Scanning technology is a wellknown technique for quickly getting three-dimensional information. It reconstructs the scanned object and builds highaccuracy and high precision 3D point clouds. At present, the TLS technology is widely used in high-precision ground information, three-dimensional measuring and surveying.

One of the technologies in producing a detailed 3D model requires a very high level of technologies such as using Light Detection and Ranging (LiDAR). By using LiDAR, data can be collected quickly and comes with high accuracy as it advantages. However, LiDAR requires high operating costs in some applications. Although LiDAR is cheap when used in huge applications, it can be too expensive when applied in smaller areas when collecting data. As the technology improves these days, 3D mapping also can be done using Unmanned Aerial Vehicle (UAV) or Terrestrial Laser Scanner. But the accuracy is different for both methods since both methods used different persperctive to acquire the data.
Moreover, Unmanned Aerial Vehicle (UAV) techniques also have gained specific attention in 3D mapping and modeling (Nex and Remondino, 2014). Mainly, the use of UAV in surveying works rose due to its lightweight and cheap cost. UAVs which are inhabited, reusable motorized vehicles and they usually fly vertically above object in few meters high. In addition, UAV could make data collection fast and comes with high resolution aerial images by utilizing UAV photogrammetric method. By considering the image overlapping, scale factors and flying altitude, the data then can be used to reconstruct the surface of model of the study area and produce highly detailed 3D mapping and modeling.

The advancement of new technologies such as TLS and UAV, it could help to provide the accurate and precise 3D models of complex objects as well as mapping purposes. According to $\mathrm{Xu}$ et al. (2014), no single sensor can acquire complete information of an object even if several multi-surveys are applied. Data integration means combination data from various sources and to provide users with a unified view of data. According to Zhang (2010) data integration typically includes the combining of the multidisciplinary data from various sources to produce quality data. Integrated data from multiple sources can improve information and facilitate the data processing task (Gruen et al., 2013).

Therefore, this study focuses on the integration between TLS and UAV. Photogrammetric method in producing complete 3D mapping that can be used for heritage documentation, mapping urban area, 3D visualization and geology investigation. The TLS will be used for the acquisition of facades while the UAV will be used for capturing the roof of an area. Additionally, this study will investigate the combination use of point clouds from UAV and TLS for modeling and surface reconstruction. From this study, it is expected that a 3D model will be produced with the final results of a complete point clouds and the orthophoto of the study area. 


\section{METHODOLOGY}

Basically, the methodology of this study can be categorized into five phases: preliminary study, data acquisition, data processing, result and analysis and conclusion and recommendations.

\subsection{Phase 1: Preliminary Study}

In the first phase of the methodology, it consists of literature review of the study to identify the issues and problems related to the research. Literature review is a very important part especially to study the fundamental of the studies regarding the research. Literature review will be related towards the problem statement. In this study, combining the point clouds from both methods is the issue as it involves lots of point clouds. Some studies have been done to identify the solution. The review is to gain knowledge, acquire more information and understanding regarding the scope of study.

\subsection{Phase 2: Data acquisition}

In this phase, data collection was carried out by using the UAV and the GLS 2000. First thing that were done are recognizing the study area and determining the flight line according to the suitable situation. DJI Inspire 1 was used to obtain the aerial images. Meanwhile, Topcon GLS 2000 was used to collect the ground data. Figure 1 shows the flowchart of data acquisitions which are divided to three parts; establishment of ground control points, aerial data collection and ground data collection.

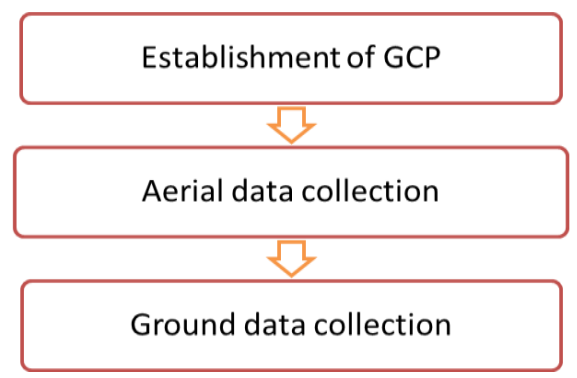

Figure 1 The flowchart in data acquisition phase

\section{Establishment of GCP}

Ground Control Point (GCP), are points on the ground with known coordinates in the spatial coordinate systems. For GCP in this study, it was established using GPS observation. Rapid static method was used and the satellites was observed using Topcon GR5 for approximately 20 minutes. In this research, GCP is determined prior to the UAV and GLS data collection because in this process, the coordinates obtained will be used in GLS data collection. All coordinates will be in WGS84 system. The GCP was setup on a point planned prior to the GPS observation. About 6 points were established for laser scanner points meanwhile about 5 points were established for UAV"s GCPs.

\section{II. : Aerial data collection using UAV}

In this process, UAV was flown over the study area to get the vertical view of the building and subsequently to obtain the images of the rooftop of the study area. Few aerial photographs will be taken by the UAV that will be further used to generate orthophoto and point clouds.
For aerial data acquisition process, a rotary UAV platform, DJI Inspire 1 model was used for the whole data acquisition to acquire images from the study area due its ability and safety where the symmetrical positions of the rotors help the UAV to maintain its planar angle. The specification of the DJI Inspire 1 used in this study is shown in the Table 1.

\begin{tabular}{|c|c|c|}
\hline No & Parameters & Specifications details \\
\hline 1 & Aircraft Model T600 & \\
\hline 2 & Weight & $\begin{array}{l}6.74 \mathrm{lbs}(3060 \mathrm{~g} \text {, including } \\
\text { propellers, battery and Zenmuse } \\
\mathrm{X} 3 \text { ) }\end{array}$ \\
\hline 3 & GPS Hovering & Vertical: \pm 1.64 feet $(0.5 \mathrm{~m})$ \\
\hline & Accuracy & Horizontal: \pm 8.20 feet $(2.5 \mathrm{~m})$ \\
\hline 4 & Max Speed & $49 \mathrm{mph}$ \\
\hline 5 & Max Flight Time & Approximately 18 minutes \\
\hline 6 & Gimbal Model & Zenmuse X3 \\
\hline 7 & Camera Name & $\mathrm{X} 3$ \\
\hline 8 & Camera Model & FC350 \\
\hline
\end{tabular}

Table 1 Specification of DJI Inspire 1

It is also important to plan the flight before flying as it is one of the important aspects in aerial mapping. Flight planning includes weather and ground conditions and time frame for photography. Mission must be carefully planned and executed according to the flight plan. A clear-weather day was determined and chosen and the UAV was flown on the day.

A very thorough planning for data acquisition is needed in order to avoid the problem of loss and cost. A flight planning shows a flight map which consists of waypoints on a topographic map showing the starting and ending points of each line. Therefore, the flight planning includes the location of study area, flight altitude and speed, flight estimated time of the study area and important details of the flight.

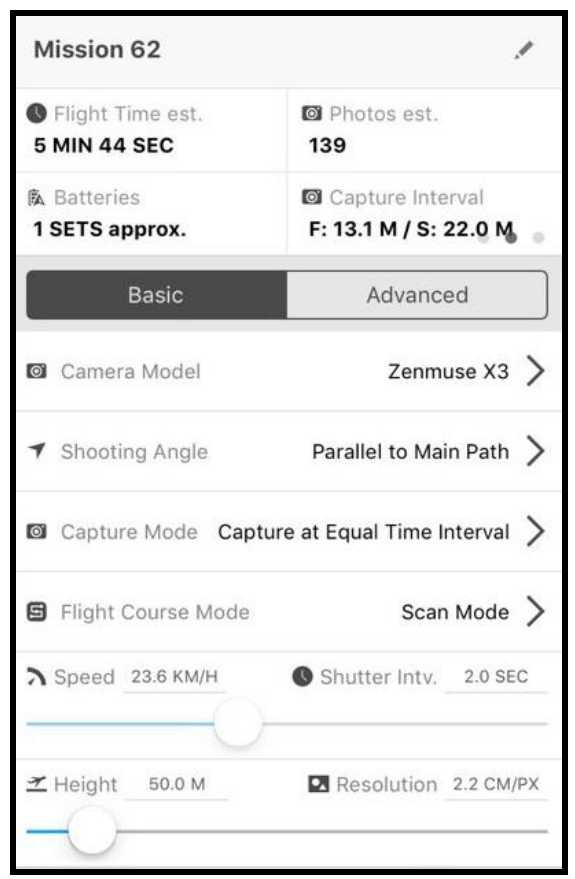

Figure 2 Settings for UAV flying 
The flying height was set up to 50 meters above ground and the overlapping was set to $70 \%$ side lap and $60 \%$ for end lap. Any higher altitude will result object far in distance meanwhile shorter altitude to the ground is not suitable. The total number of flight strips is 7 strips and the flight took about 5 minutes. The study area for data acquisition involved was the rooftop of T06 building.

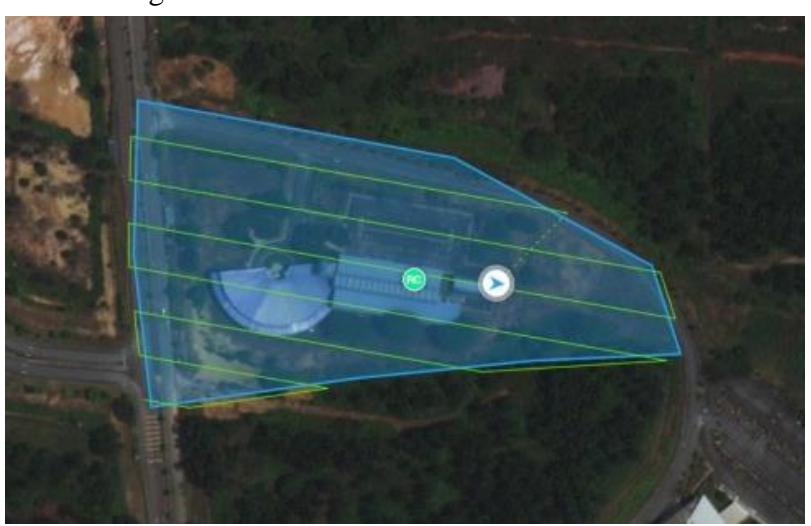

Figure 3 Area of flying and monitoring

\section{Ground data collection using GLS 2000}

Ground data in this study was collected by using Geodetic Laser Scanner (GLS) as it has the advantages of geodetic positioning in the instrument. GLS is a type of Terrestrial Laser Scanners that allows traversing. By using GLS, it is easy to position the laser scanner by inserting the known coordinates of the point and collect the point clouds of the building. Laser scanner was used to collect point clouds of exterior facade of the building. One of limitation using laser scanner is that it cannot collect the surface or roof of a study area.

\begin{tabular}{|c|c|}
\hline GLS 2000 Specifications & Specifications Details \\
\hline Type & Pulse (ToF - Time of Flight) \\
\hline Laser Class & 3R (High Speed / Standard) \\
\hline & 1M (Low Power) \\
\hline Scan Rate (High Speed) & Up to 120,000 points/sec \\
\hline Spot Size & $4 \mathrm{~mm}$ at $20 \mathrm{~m}(\mathrm{FWHM})$ \\
\hline Scanning Control System & On-board \\
\hline Data Storage & SD card \\
\hline Target Detection & $3 "$ at $50 \mathrm{~m}$ \\
\hline Accuracy & \\
\hline System performance & Standard Mode : $350 \mathrm{~m}$ at $90 \%$ \\
\hline (Maximum range) & $\begin{array}{l}\text { High Speed Mode : } 210 \mathrm{~m} \text { at } \\
90 \%\end{array}$ \\
\hline & Low Power Mode : $210 \mathrm{~m}$ at $90 \%$ \\
\hline Single Point Accuracy & $\begin{array}{l}\text { Distance }-3.5 \mathrm{~mm} \\
\text { Angle }-6 "\end{array}$ \\
\hline
\end{tabular}

Table 2 Specification of GLS 2000

Data acquisition using Topcon Geodetic Laser Scanner 2000 was carried out in this study by applying traversing technique. The laser scanner was located at each of the GCP collected earlier with addition few points on the ground to complete the traverse done by the laser scanner. Traversing technique (also known as Occupation / Backsight method) means it has a backsight station and a front station and instrument occupy on the current station. The occupied station of laser scanner and backsight station must be setup on the known point which has been obtained from the traverse or GPS survey for direct approach.
The survey coordinates of scanning data for this method are calculated directly relative to the known point (Mat Zam et al., 2018). It is a method conducted similar to the general survey for cadaster or topography survey. Traversing is a type of survey in which a number of connected survey lines form the framework and the directions and lengths of the survey lines are measured with the help of an angle measuring instrument.

Firstly, the laser scanner Topcon GLS 2000 needs to be set on a tripod and followed by leveling and centering the instrument. This step is important because the instrument must be leveled correctly and plumbed directly on top of the station or points on the ground in order to minimize the error in measurement.

After setting out the laser scanner, bearing and coordinates of the back station were set in order to define the fore station. The line of sight for both back station and fore station with the laser scanner is required.

In this study, the 3D point clouds were collected using medium resolution mode $(6.3 \mathrm{~mm}$ of point spacing for both horizontal and vertical spacing at the range of $10 \mathrm{~m}$ ). Each scan took around 7 minutes to 10 minute including the addition for capturing image (5 images at least) of each angle of the station. At the same time, the scan mode was set to 'High Speed' and the pulse select was set to 'Last'. The distance for high speed is about $130 \mathrm{~m}$. Moreover, the ideal distance between scanner and surrounding features is not to exceed $350 \mathrm{~m}$. All of these steps were repeated for the rest of the stations until the traverse loop is closed.

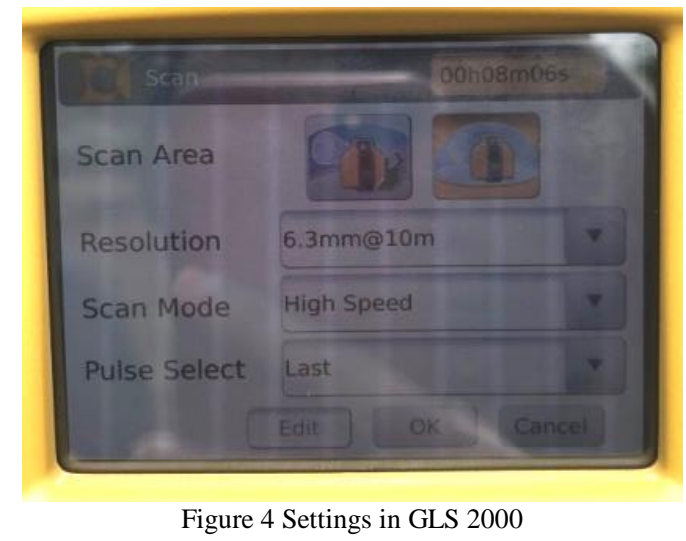

\subsection{Phase 3: Data Processing}

This section briefly describes data processing stages that have been used in this research. In this processing phase, it is divided into 4 parts which are stated in Figure 5.

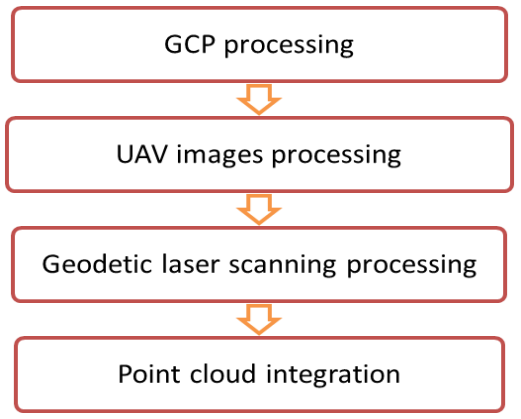

Figure 5 Flowchart in data processing phase 


\section{GCP processing}

In order to know the coordinates of each Ground Control Points (GCP), the raw data collected from GPS is processed using the software Trimble Total Control (TTC) published by Trimble Inc. TTC provides geodetic control capability plus processing and tools to enable GPS data to be processed with analysis and reports. It is the first data processing in this thesis and it need to be done first as the coordinates will be used to process later in $\mathrm{UAV}$ and laser scanning processing.

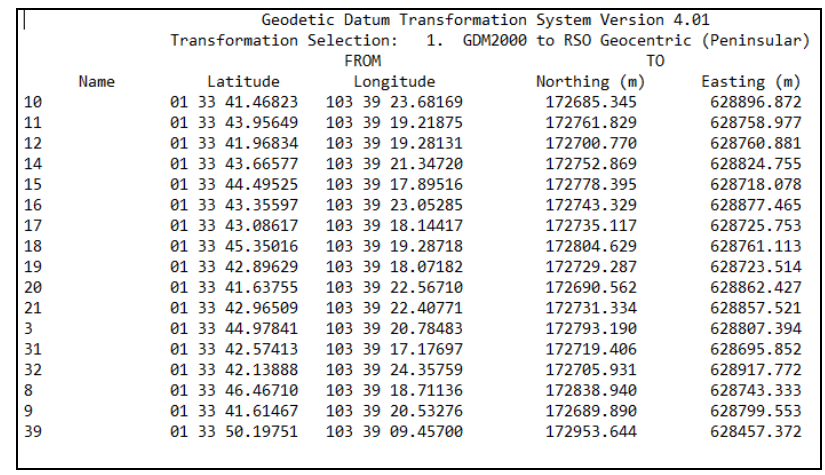

Figure 6 Coordinates obtained after processing

\section{UAV images processing}

The aerial image data obtained from UAV will go through few processing steps before the production of the orthophoto and the generation of point clouds. The processing software that was used to produce those end products is Pix4Dmapper Pro. The processing steps will be including the initial processing, point cloud and mesh generation and last is DSM, orthomosaic/orthophoto generation.

\section{Ground data processing}

The data collected from GLS 2000 is processed using Scanmaster software. The data went through few steps consist of data importing, data registration and data cleaning. Figure below shows the steps of processing the 3D point cloud generated from the TLS.

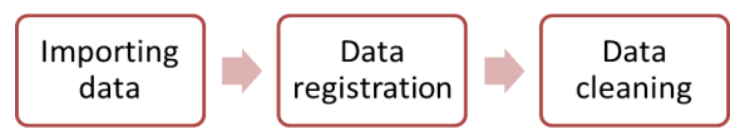

Figure 7 Steps used in Scanmaster Software

Using GLS 2000, users can skip the part to create tie points because it already has the advantage of geodetic positioning.
Coordinates of known points has already inserted in the field and eventually georeferencing part can also be skipped. Georeferencing is a process that enables to reorient the entire dataset to the corresponding coordinates of the tie point constraints measured using a GPS or total station with the coordinate from laser scanner.

Cleaning process means user need to clean the unwanted point clouds collected during the scans. For example, trees that being scanned needs to be cleaned out from the point cloud. In this study, Autodesk Recap is used in this study to carry out the cleaning process.

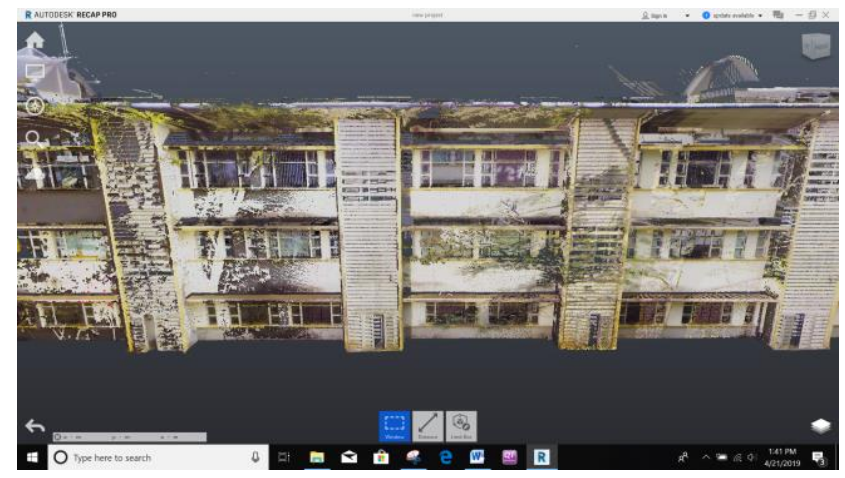

Figure 8 Example of unwanted point clouds in the study area

\section{Integration of point clouds from UAV and GLS}

After all of the aerial data and ground data has been processed, each of them generated a set data of point clouds and that point clouds will be used to merge into one layer. In order to merge, it is really important to make sure from the start that both of the point clouds data sets were in the same coordinate system. That is why known points collected by GPS plays an important role in this study. Earlier in this study, aerial data has been processed with GCP where the GCP is in RSO (Peninsular) coordinate system. Subsequently, ground data from GLS 2000 also has been registered with the known points of the same coordinate system. In this study, software named Cloud Compare has been chosen to operate the integration process.

The integration process for UAV and TLS is made through the registration method by using man-made. The registration using man-made is chosen due to the most prominent elements from both datasets. Selected examples of man-made such as roof edges and building corners. A total 6 point of roof edges and building corners has been chosen for the integration process and aligning both datasets into 1 dataset as shown in Figure 9. The accuracy of registration between both data sets is shown in Figure 10.

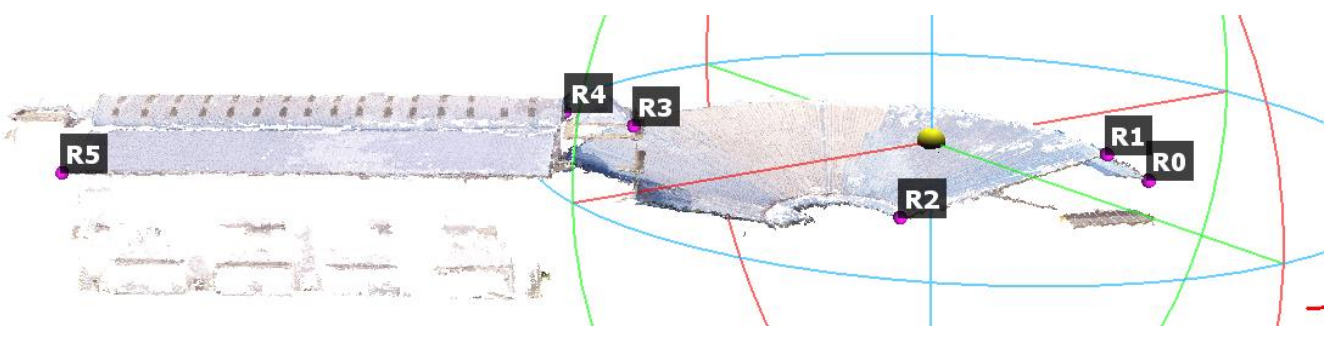


The International Archives of the Photogrammetry, Remote Sensing and Spatial Information Sciences, Volume XLII-4/W16, 2019 6th International Conference on Geomatics and Geospatial Technology (GGT 2019), 1-3 October 2019, Kuala Lumpur, Malaysia

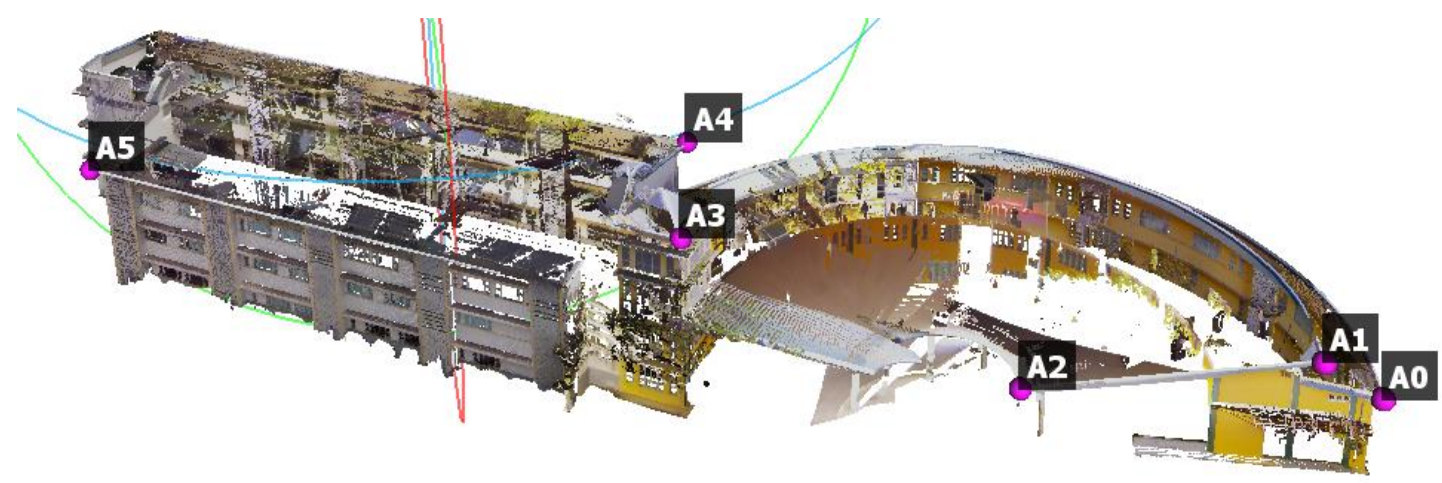

Figure 9 The selected points to perform the merging process

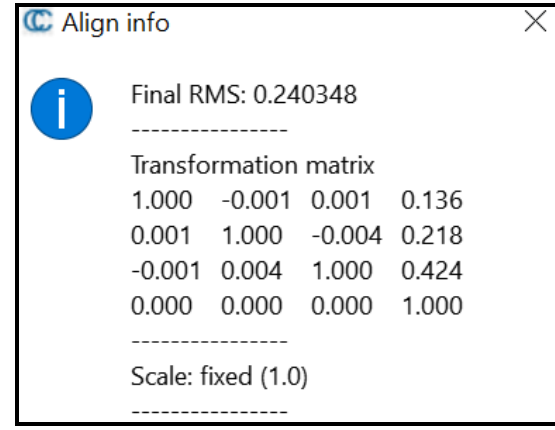

Figure 10 The accuracy of registration of the selected points

\section{RESULTS AND DISCUSSION}

This chapter shows the result of the study and discussed the approaches of data analysis which conducted in this research. These include validation of UAV data, TLS data and integration accuracy assessment. In UAV data validation, the data were analyzed through the value of RMS error between the value of GCP and the value of coordinates of the same point on orthophoto. Meanwhile, TLS data is validated through the error of backsight calculated and through the value of RMSE of the coordinates. Subsequently, the integration process were analyzed though the value of residual of the measurements that were taken to check the accuracy assessment.

\subsection{Results}

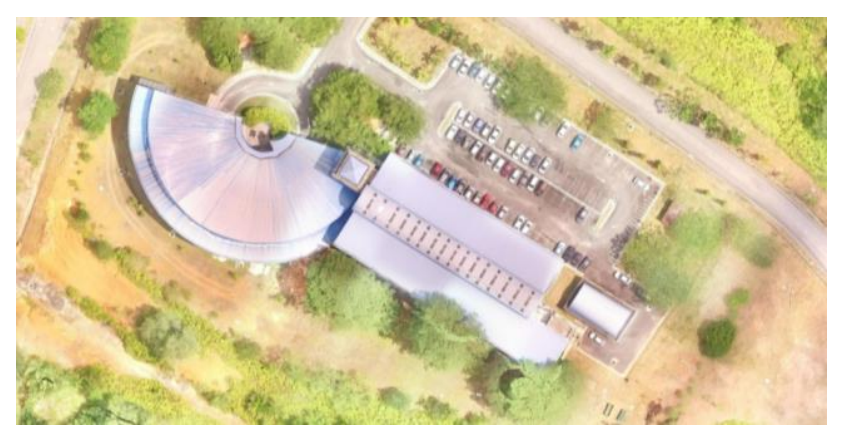

Figure 11 Orthophoto of the study area

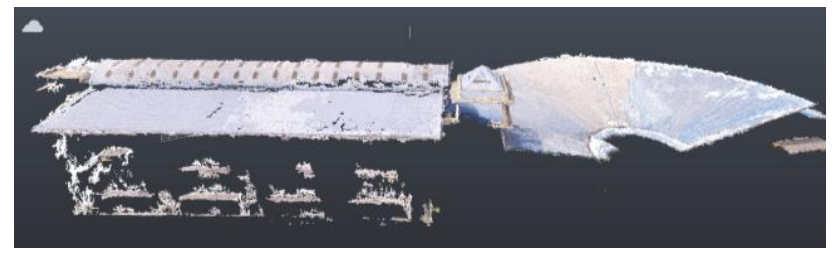

Figure 12 Point cloud of roof generated from Pix4D Software

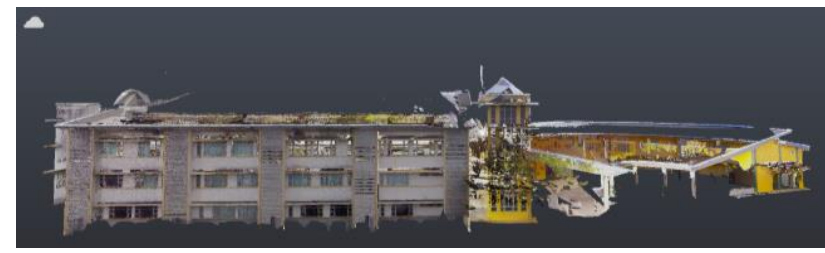

Figure 13 Front View of the building facades

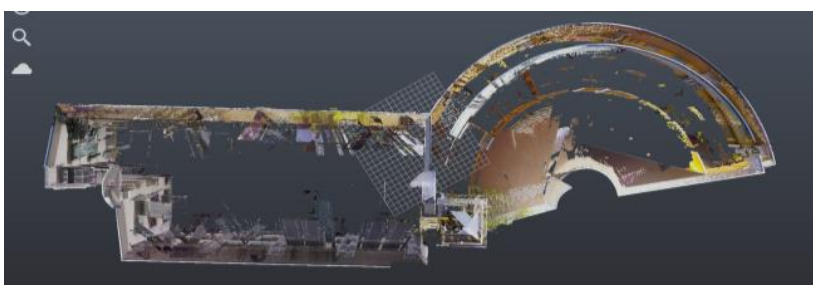

Figure 14 Top view of building

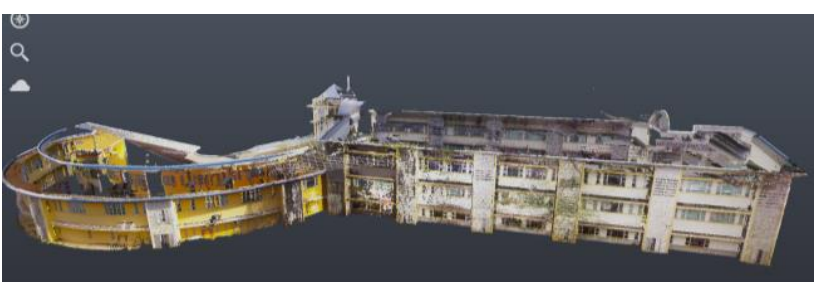

Figure 15 Back View of the building facades 


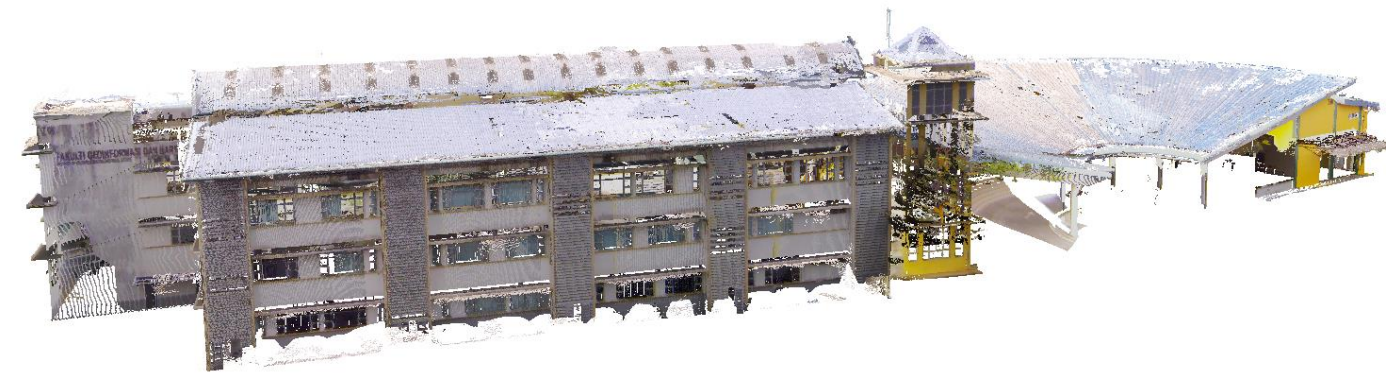

Figure 16 Merged point clouds from UAV and TLS

At the end of the process two point clouds were generated: the first was obtained by the images and the second by using the laser scanner. The two datasets were integrated from TLS point cloud and orthophoto. Data merging was facilitated by the fact that the two clouds were in the same reference system, obtaining fully consistent results in terms of accuracy.

\subsection{Analysis}

\section{UAV data validation}

In this research, five points were used as checkpoints to check the accuracy of UAV processing images. The reliability of these dataset was evaluated through the value of root mean square error between the coordinates of the points on orthophoto generated and the coordinates from GPS. The lower the value of RMSE indicates a higher accuracy. The value of RMSE is shown in Table 3.

\begin{tabular}{|c|c|c|c|c|c|c|}
\hline \multirow{2}{*}{$\begin{array}{c}\text { Check } \\
\text { Points }\end{array}$} & \multicolumn{2}{|c|}{ Coordinates from UAV } & \multicolumn{2}{c|}{ Coordinates from GPS } & \multicolumn{2}{c|}{ Differences } \\
\cline { 2 - 7 } & $\mathrm{X}$ & $\mathrm{Y}$ & $\mathrm{X}$ & $\mathrm{Y}$ & $\Delta \mathrm{X}$ & $\Delta \mathrm{Y}$ \\
\hline GCP 31 & 628696.273 & 172719.273 & 628695.852 & 172719.406 & -0.421 & 0.133 \\
GCP 15 & 628718.283 & 172778.260 & 628718.078 & 172778.395 & -0.205 & 0.135 \\
GCP 3 & 628807.405 & 172793.296 & 628807.394 & 172793.190 & -0.011 & -0.106 \\
GCP 16 & 628877.402 & 172743.288 & 628877.465 & 172743.329 & 0.063 & 0.041 \\
GCP 32 & 628917.440 & 172705.722 & 628917.722 & 172705.391 & 0.282 & -0.331 \\
\hline \multicolumn{3}{r|}{} & RMSE & \pm 0.246 & \pm 0.178 \\
\cline { 3 - 7 } & & & Average & \multicolumn{2}{|c|}{$0.212 \mathrm{~m}$} \\
\hline
\end{tabular}

Table 3 RMSE for UAV data

\section{TLS data validation}

For TLS part, the analysis of this divided to two parts. Thus, the first part of the analyses conducted in this stage is based on the backsight error value obtained during the registration of backsight at the field. The accuracy of TLS data is analyzed through the value of backsight error since the technique used is the traversing method or called as backsight and occupation method. If tie points method were used, then the tie point's constraints should be analysed. Since this study uses the backsight and occupation method, the backsight errors were already computed by the software itself. To check the quality report, go to View $\rightarrow$ Windows $\rightarrow$ Object Properties. There were 11 backsight errors generated from 12 stations. Thus, the errors from ST 02 to ST 12 are displayed in Table 4.

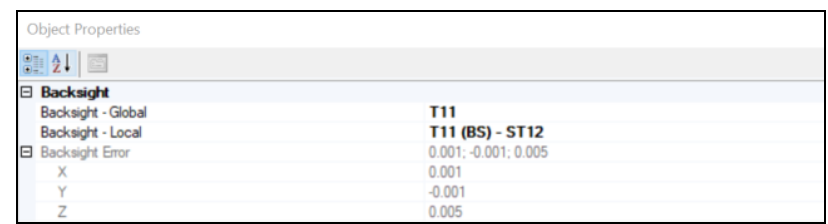

Figure 17 Backsight error obtained from Scanmaster

\begin{tabular}{|c|c|c|c|}
\hline Station & $\mathrm{X}$ & $\mathrm{Y}$ & $\mathrm{Z}$ \\
\hline ST 02 & -0.006 & -0.009 & -0.084 \\
ST 03 & -0.001 & 0.000 & 0.007 \\
ST 04 & -0.001 & 0.001 & 0.014 \\
ST 05 & -0.014 & 0.000 & -0.040 \\
ST 06 & 0.006 & -0.004 & 0.030 \\
ST 07 & 0.000 & 0.002 & 0.016 \\
ST 08 & 0.004 & -0.002 & 0.013 \\
ST 09 & 0.000 & 0.000 & 0.084 \\
ST 10 & 0.002 & -0.001 & 0.010 \\
ST 11 & 0.003 & 0.001 & -0.007 \\
ST 12 & 0.001 & -0.001 & 0.005 \\
Average & 0.0005 & 0.0011 & 0.0044 \\
\hline Average & \multicolumn{3}{|c}{$0.0009 \mathrm{~m}$} \\
XYZ & \multicolumn{3}{|l}{} \\
\hline
\end{tabular}

Table 4 Backsight error for 12 stations

Second part validation of TLS data that were used in this study is through the value of RMS error calculated between the coordinates of TLS"s known point and the coordinates from GPS. 3 points were used to check the value of RMSE. The average of RMSE is 0.044 shown in Table 5. 
The International Archives of the Photogrammetry, Remote Sensing and Spatial Information Sciences, Volume XLII-4/W16, 2019 6th International Conference on Geomatics and Geospatial Technology (GGT 2019), 1-3 October 2019, Kuala Lumpur, Malaysia

\begin{tabular}{|c|c|c|c|c|c|c|c|c|c|}
\hline \multirow{2}{*}{ POINTS } & \multicolumn{3}{|c|}{ TLS } & \multicolumn{3}{|c|}{ GPS } & \multicolumn{3}{|c|}{ Differences } \\
\hline & $X$ & $\mathrm{Y}$ & $\mathrm{Z}$ & $X$ & $\mathrm{Y}$ & $\mathrm{Z}$ & $\Delta \mathrm{X}$ & $\Delta \mathrm{Y}$ & $\Delta \mathrm{Z}$ \\
\hline GCP 11 & 628758.984 & 172761.840 & 27.395 & 628758.977 & 172761.829 & 27.3593 & -0.007 & -0.011 & -0.0357 \\
\hline GCP 14 & 628824.777 & 172752.887 & 27.085 & 628824.755 & 172752.869 & 26.9733 & -0.022 & -0.018 & -0.1117 \\
\hline GCP 21 & 628857.553 & 172731.354 & 27.166 & 628857.521 & 172731.334 & 27.0585 & -0.032 & -0.020 & -0.1075 \\
\hline & & & & & & \multirow{2}{*}{$\begin{array}{c}\text { RMSE } \\
\text { Average }\end{array}$} & \pm 0.023 & \pm 0.017 & \pm 0.092 \\
\hline & & & & & & & \multicolumn{3}{|c|}{$0.044 \mathrm{~m}$} \\
\hline
\end{tabular}

Table 5 Coordinates from TLS and GPS

Integration accuracy assessment

The integration data have to go through the accuracy assessment process to ensure the accuracy of the data in high-quality. The analysis carried out by making a comparison between the integration data with field work dimension survey using total station. Field work dimension survey is used as a bench mark for comparing process where the example of dimension used such as measurement of floor, door, window, balconies, stairs and many others.

In this study, the comparison is done between the values from the distance taken from the integrated point cloud data with the values of distance taken from the field work data. The comparison is calculated and shown in Table 6 .

\begin{tabular}{|c|c|c|c|}
\hline Samples & Point cloud & Field work & Residuals \\
\hline 1 & 8.834 & 8.733 & -0.101 \\
2 & 3.161 & 3.222 & 0.061 \\
3 & 2.957 & 3.003 & 0.046 \\
4 & 1.670 & 1.802 & 0.132 \\
5 & 12.611 & 12.753 & 0.142 \\
6 & 11.976 & 11.988 & 0.012 \\
7 & 4.826 & 4.859 & 0.033 \\
8 & 9.510 & 9.575 & 0.065 \\
9 & 2.465 & 2.527 & 0.062 \\
10 & 0.823 & 0.803 & -0.02 \\
11 & 12.589 & 12.387 & -0.202 \\
12 & 12.405 & 11.932 & -0.473 \\
13 & 64.021 & 63.589 & -0.432 \\
14 & 8.629 & 8.825 & 0.196 \\
15 & 1.132 & 1.132 & 0 \\
16 & 2.313 & 2.384 & 0.071 \\
17 & 2.804 & 2.908 & 0.104 \\
\hline \multicolumn{2}{|r|}{} & RMSE & $\pm 0.183 \mathrm{~m}$ \\
\hline
\end{tabular}

Table 6 The residuals between distance from point cloud and field work

The residuals are then used to calculate the RMSE value. The RMSE from the residuals is $0.183 \mathrm{~m}$. Root Mean Square Error (RMSE) is the standard deviation of the residuals (prediction errors). Residuals are a measure of how far from the regression line data points are; RMSE is a measure of how spread out these residuals are.

After being satisfied with the integration result obtained, the integrated data is utilized to generate a $3 \mathrm{D}$ model as a final product of this study. Sketch Up software is used to build the 3D model of T06 FBES building. Figure 18 shows the 3D model of T06 building as a final product of integration points cloud process.

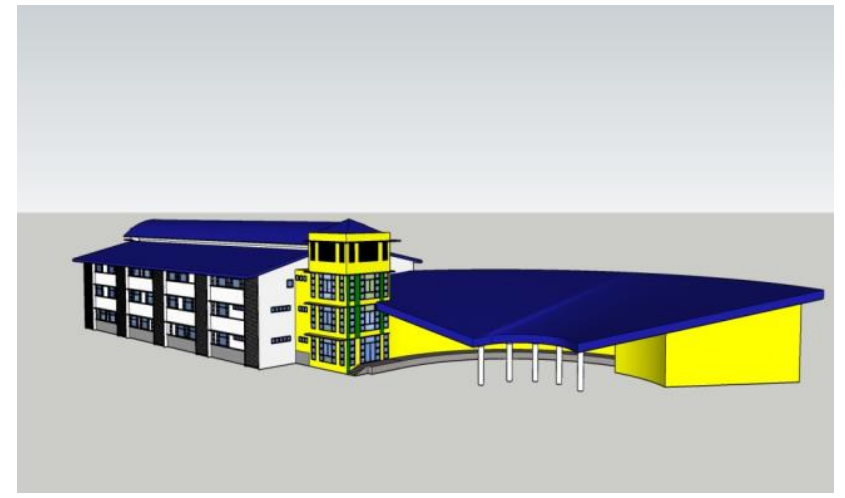

Figure 17 3D model of T06 FBES building

\section{SUMMARY}

This study has discussed the possibility of integration between UAV and TLS. The main purpose of integration was to produce a complete $3 \mathrm{D}$ model of a building through the generation of point clouds. The integration was facilitated by the fact that the two point clouds are in the same coordinate system. In this study, the coordinate system that is used is Malaysian Rectified Skew Orthomorphic (Peninsular). In this study, the use of Topcon GLS 2000 also facilitates in data acquisition and processing since it has the geodetic positioning advantages. Due to that, the point cloud generated from the laser scanner can be directly imported into the software for integration purposes.

From the study, there are some recommendations that can be considered for further study. The recommendations are as follows:

a) GPS values should be obtained through the field work method since this study are contains many obstruction such as trees and building. The errors could be very high due to multipath at the study area.

b) Avoid flying at a very high altitude and during middle of the day where the sun is at the top to avoid overexposed images. When the images are overexposed, it is hard to locate the location of GCP for georeferencing. Thus, the accuracy will be affected.

\section{REFERENCES}

Abdullah, C. C. K., Baharuddin, N., Ariff, M., Majid, Z., Lau, C., Yusoff, A., et al. (2017). Integration of Point Clouds Dataset from Different Sensors. The International Archives of Photogrammetry, Remote Sensing and Spatial Information Sciences, 42, 9. 
Ahmad, A. (2011). Digital mapping using low altitude UAV. Pertanika Journal of Science and Technology, 19(S), 51-58.

Aicardi, I., Dabove, P., Lingua, A. M., and Piras, M. (2016). Integration between TLS and UAV photogrammetry techniques for forestry applications. iForest-Biogeosciences and Forestry, $10(1), 41$.

Azmi, S. M., Ahmad, B., and Ahmad, A. (2014). Accuracy assessment of topographic mapping using UAV image integrated with satellite images. Paper presented at the IOP Conference Series: Earth and Environmental Science, 012015.

Demirel, A., Akdeniz, H., and Aksu, O. (2004). Two functional software for internal use; flight planning and presenting of digital orthophotos. Paper presented at the Proceedings of Commission IV, XXth ISPRS Congress, 12-23.

Greffet, J.-J., Carminati, R., Joulain, K., Mulet, J.-P., Mainguy, S., and Chen, Y. (2002). Coherent emission of light by thermal sources. Nature, 416(6876), 61.

Gruen, A., Huang, X., Qin, R., Du, T., Fang, W., Boavida, J., et al. (2013). Joint processing of UAV imagery and terrestrial mobile mapping system data for very high resolution city modeling. Int. Arch. Photogramm. Remote Sens. Spat. Inf. Sci, 175-182.

Haddad, N. A. (2011). From ground surveying to 3D laser scanner: A review of techniques used for spatial documentation of historic sites. Journal of King Saud University-Engineering Sciences, 23(2), 109-118.

Ma, L., Li, M., Tong, L., Wang, Y., and Cheng, L. (2013). Using unmanned aerial vehicle for remote sensing application. Paper presented at the Geoinformatics (GEOINFORMATICS), 2013 21st International Conference on, 1-5.

Mat Zam, P., Fuad, N., Yusoff, A., and Majid, Z. (2018). Evaluating the Performance of Terrestrial Laser Scanning for Landslide Monitoring. International Archives of the Photogrammetry, Remote Sensing and Spatial Information Sciences, 42(4/W9).

Nex, F., and Remondino, F. (2014). UAV for 3D mapping applications: a review. Applied geomatics, 6(1), 1-15.

Remondino, F., Barazzetti, L., Nex, F., Scaioni, M., and Sarazzi, D. (2011). UAV photogrammetry for mapping and $3 \mathrm{~d}$ modeling-current status and future perspectives. International Archives of the Photogrammetry, Remote Sensing and Spatial Information Sciences, 38(1), C22.

Xu, Z., Wu, L., Shen, Y., Li, F., Wang, Q., and Wang, R. (2014). Tridimensional reconstruction applied to cultural heritage with the use of camera-equipped UAV and terrestrial laser scanner. Remote sensing, 6(11), 10413-10434.

Yastikli, N. (2007). Documentation of cultural heritage using digital photogrammetry and laser scanning. Journal of Cultural Heritage, 8(4), 423-427. 